\title{
Bing Zhi: pioneer of modern biology in China
}

\author{
Ming Li, Le Kang ${ }^{凶}$ \\ Beijing Institutes of Life Science, Chinese Academy of Sciences, Beijing 100101, China \\ $\checkmark$ Correspondence: Ikang@ioz.ac.cn
}

Located in the lobby of the Institute of Zoology at Chinese Academy of Sciences, is a bronze statue of Dr. Bing Zhi. Many passers-by, especially the young ones, would ask who this person is and what he has accomplished. The short answer is, according to the plate of the statue, that he is a pioneer zoologist and educator and the founder of modern biology in China. The more detailed answer involves the word "first" for quite a few significances: As a biologist, Bing Zhi is the co-founder of the first non-governmental scientific society of China, the co-founder of the first Chinese scientific journal, the founder of the first biology department in China, the founder of the first biological research institute in China, and the founder of China Zoological Society; as an educator, he trained many young men who later became renowned specialists in their own areas.

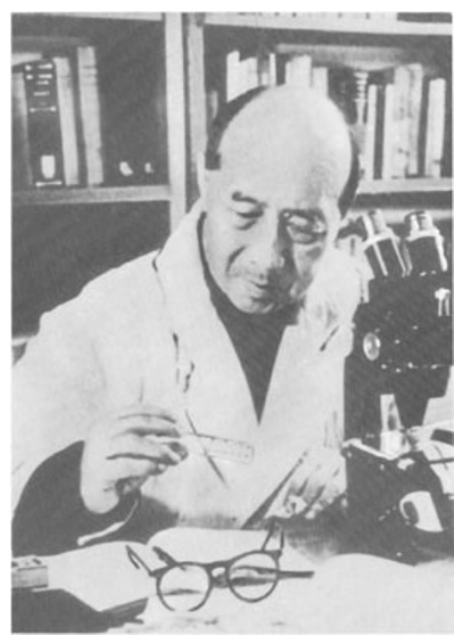

Dr. Bing Zhi (April 9, 1886-February 21, 1965) (from Bing Zhi Selection (《秉志文存》))

Born in 1886, Bing Zhi had received traditional education in his home province Henan, and passed the imperial exams to become a first-degree scholar at age 17. After four-year preparatory study at the Imperial Capital University in Peking, he was sent to the United States for higher education, supported by the Boxer Indemnity Fund. During his study in Beijing, he had shown great interests in natural sciences and was particularly inspired by Charles Darwin's Origin of Species, which explained why he later chose to study entomology under Prof. J. G. Needham when he came to Cornell University. After getting B.S. degree in 1913, he continued for graduate study in Cornell University and became the first Chinese to get Ph.D. degree in entomology. Prof. Needham called him "a scholar, a respectable colleague and a dearest friend". Later, he went to the Wistar Institute of Anatomy and Biology and studied vertebrate neurology under Prof. H. H. Donaldson, who is a famous neurologist. During this period, he also registered classes in University of Pennsylvania, which provided solid knowledge foundation for his wide range research work in future.

Even when he was a student at Cornell University, Bing Zhi had always been active in promoting modern science in China. In 1915, Bing Zhi and other Chinese students at Cornell founded the first non-governmental academic organization of China-the Science Society of China. He was also the co-founder of the first Chinese scientific journal-Ke Xue (meaning 'Science' in Chinese). The main purpose of the journal was to introduce modern science to ordinary people in China. During the first couple of years, Bing Zhi published 15 articles on $\mathrm{Ke} X u e$, including the first Chinese article on medical insects-Malaria Mosquitos.

When he returned from United States in 1920, Bing Zhi was hired by the Nanjing Normal College, which became Southeast University in 1921, then National Central University in 1928. At the Nanjing Normal College, Bing Zhi taught Zoology in the department of Agriculture. Instead of the old-fashioned teaching style where selected animals from each phylum were introduced to the students one by one, Bing Zhi used the evolution theory to connect animals from different phyla. His coherent teaching style made zoology very popular in his class. In fact, more than half of the students changed their major from Agriculture to Zoology, largely due to Bing Zhi's 
influence. Back then, some of the Chinese universities and colleges had a department of natural sciences, but none had a department of biology. Because of Bing Zhi's continuous efforts and influence, the Southeast University decided to establish the Department of Biology, which would be the first biology department in China. The department, with Bing Zhi as the Dean, comprised of two divisions-Zoology and Botany, of which Bing Zhi and botanist Chongpeng Qian were the chairs, respectively. The newly-established department was underfunded for lab equipments and specimens, so Bing Zhi and other faculties used their own savings to buy equipments, such as section machines. Most of the zoological specimens were collected by Bing Zhi and his students in Zhejiang and Shandong provinces during summer breaks.

Meanwhile, the Science Society of China moved back to China and had its physical location in Nanjing. As a founding member of the society, Bing Zhi initiated the establishment of the Biological Laboratory of the Science Society of China in 1922. While the Department of Biology at Southeast University was more teaching-oriented, the Laboratory was getting more focused on research, especially Taxonomy and Morphology. The Laboratory went through a financially difficult time at the beginning, just like the Department of Biology at Southeast. Fortunately, the Laboratory's publication, Contributions from the Biological Laboratory of the Science Society of China, received quite a lot of attention and praises, thereby brought donations to the Laboratory. The biggest sponsor was the China Foundation for the Promotion of Education and Culture, an organization set up in 1924 to manage the Boxer Indemnity Fund. With the yearly donation from the China Foundation, the Laboratory was able to build a two-story building for the labs, and expanded its research focuses from taxonomy to physiology, biochemistry and genetics.

As time went by, it appeared increasingly urgent for Bing Zhi and his colleagues to set up another institute in the northern China so they could study the animals and plants in the north. Again, the idea was applaused by the China Foundation and its director Yuanlian Fan, who passed away less than one year before the launch of the new institute. Even after his death, Fan's family continued to support the institute and even donated his old house to accommodate the institute. When the new institute was finally launched in Beijing in 1928, it was named 'Fan Memorial Institute of Biology' in memory of Yuanlian Fan. Again, Bing Zhi was made Director of the institute. Running two institutes at the same time, one in northern China and the other in the south, Bing Zhi had to be more diligent than ever. Financially, since the funds donated to the institute were never sufficient for the equipments and specimens, Bing Zhi voluntarily used his own salary to cover transportation costs between the two cities. With the devotion of Bing Zhi and his colleagues, along with relatively abundant funding, the Fan Memorial Institute of Biology soon expanded to an extent that the original building (Fan's old house) could not accommodate. With the help of the Education Ministry and the China Foundation, a new laboratory building for the institute was constructed and put into use in 1931. By 1935, the institute became the number one zoological research institution in the country and many scholars from universities and other institutes kept coming in to carry out their research projects.

Other than the one department and two institutes mentioned above, Bing Zhi also worked in Xiamen University, Fudan University, Institute of Hydrobiology, and Institute of Zoology of Chinese Academy of Sciences. He worked in laboratory till the day before he passed away. During over 40 years of his academic life, Bing Zhi accomplished significant achievements in morphology, physiology, taxonomy, entomology, paleontology, etc., especially in anatomy and neurology. He emphasized the significance to correlate morphological structure to physiological functions, and vice versa. His productive research publications since the Ph.D. study won worldwide recognition.

Bing Zhi had taught and trained hundreds of young people.

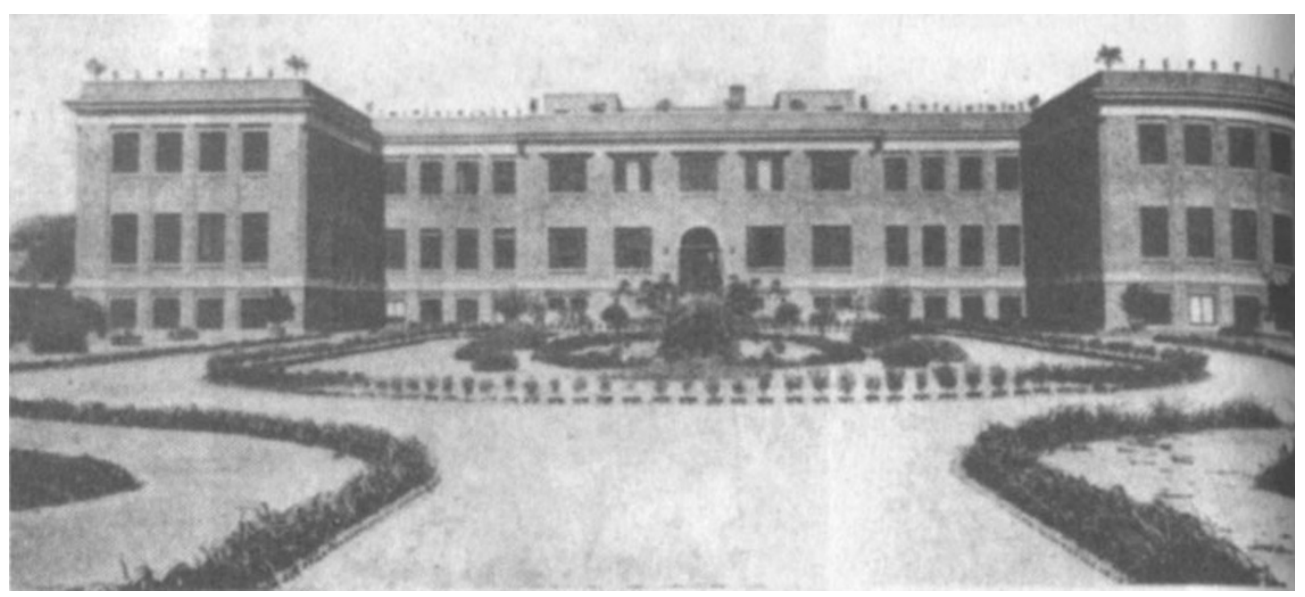

The new laboratory building of the Fan Memorial Institute of Biology (from Unforgettable Xiansu Hu (《不该遗忘的胡先骕》)) 
Most of them later became biologists and educators themselves, and followed his steps to further contribute to the life science in China. At the old age, he also donated his house and private library with over three thousand books to the country. He is an exact example of the old-generation Chinese scientists who devoted his whole life to science and the country. Together with the fact that he first brought modern biology to China, it would be appropriate to deem Bing Zhi as the pioneer of modern biology in China.

\section{REFERENCES}

Zhai, Q., and Hu, Z. (2006). Bing Zhi Selection. Beijing, Peking University Press. (翟启慧, 胡宗刚. (2006). 秉志文存. 北京, 北京大 学出版社)

Hu, Z. (2005). History of Fan Memorial Institute of Biology. Jinan, Shandong Education Press. (胡宗刚. (2005). 静生生物调查所史稿. 济南, 山东教育出版社)

$\mathrm{Hu}$, Z. (2005). Unforgettable Xiansu Hu. Wuhan, Changjiang Literature \& Art Press. (胡宗刚. (2005). 不该遗忘的胡先骕. 武汉, 长江文艺出版社)

Schneider, L. (2005). Biology and revolution in twentieth-century China. Lanham, Rowman \& Littlefield Publishers. 